Journal of Social and Development Sciences

Vol. 3, No. 10, pp. 335-341, Oct 2012 (ISSN 2221-1152)

\title{
N Dama Cattle Conservation: The Potential Roles of Artificial Insemination and the National Policy
}

\author{
${ }^{1}$ Olaniyan, Olawale Festus, ${ }^{2}$ Hiemstra, Sipke-Joost \\ ${ }^{1}$ Wageningen University, Wageningen, the Netherlands \\ ${ }^{2}$ Wageningen University and Research Centre, Lelystad, the Netherlands
}

\begin{abstract}
Regular access to genetically superior bulls from an open nucleus breeding system is an impetus for N'Dama cattle utilization and conservation. However, shortage in the number of bulls that could be distributed to the farmers for subsequent breeding remains a challenge in some countries of West Africa. In this regard, the potential benefit of artificial insemination (AI) and the roles of national policy were assessed. The open nucleus-breeding scheme of International Trypanotolerance Center (ITC) in the Gambia was used as a case study and the research questions were answered with literature review, focus group discussion, and Likert-scale questionnaire. Introduction of AI into the breeding scheme of N'Dama cattle can create higher selection intensity and promote a wider dissemination of genetic gain made at the nucleus. With improved AI techniques, a better use of improved N'Dama bulls can be achieved. Notwithstanding, there are concerns about low pregnancy rate, quality of the semen, inadequate knowledge of AI technicians, and the regular availability of quality bulls. For the Gambian national policy, the environmental component is the most relevant for conservation of N'Dama cattle. This can be buttressed with more flexibility and a clearer communication of the objectives through workshops and local media.
\end{abstract}

Keywords: N'Dama, breeding, conservation, artificial insemination, policy

\section{Introduction}

The characteristic resistance of N'dama cattle to parasitic infection such as trypanosomiasis and also the ability of this breed to tolerate low quality feed when compared to the Zebu breed are among the factors for its preference by the small-scale farmers (Mattioli, Pandey, Murray, \& Fitzpatrick, 2000). However, to sustain the unique characteristics of N'Dama cattle, there is a need to adequately breed, conserve and prevent this breed from further dilution of its genetic traits. The first initiative in this direction started in the mid-1990s with the establishment of an open nucleus breeding scheme (ONBS) in the Gambia (Dempfle \& Jaitner, 2000). Unfortunately, the scheme is suffering a setback from the collapse of multipliers' association and then the reduced number of nucleus animals that could be disseminated to the farmers. According to Kahi \& Rewe (2008) and Van Arendonk (2011) who independently gave overview of reproductive technology in the developing countries, artificial insemination (AI) can be considered for animal breeding purposes. However, none of these studies mentioned the factors that need to be considered for the adoption of AI. In this regard, this exploratory research is aimed at identifying the factors, which determine the possibility of using AI in disseminating genetically proven N'Dama bulls as a complement to the system, which involves transfer of live animals. In addition, the extent to which the existing Gambian agricultural policies can be used to stimulate conservation of N'Dama breed of cattle was investigated. The underline framework for this research as depicted in Figure 1 is based on the hypothesis that a wider dissemination and continuous access of the farmers to genetically improved bulls through AI will encourage better utilization of N'Dama cattle. On the other hand, a better utilization of genetic resources such as semen can enhance sustainable conservation of an animal (Notter, 2004). The research questions were based on the main objectives of PROGEBE (Regional Project on Sustainable Management of Endemic Ruminant Livestock in West Africa) which include how to sustainably utilize and conserve the biodiversity of endemic ruminant livestock in physical and institutional environments. In addition, the outcome of this research is important for breeding decisions in the program of ITC (the institution with the responsibility of N'Dama cattle genetic improvement in West Africa). The answers to policy related questions are intended to provide empirical evidence for the current conservation activities and to generate information for future making decisions. 
Figure 1: A Schematic Description of the Research Framework

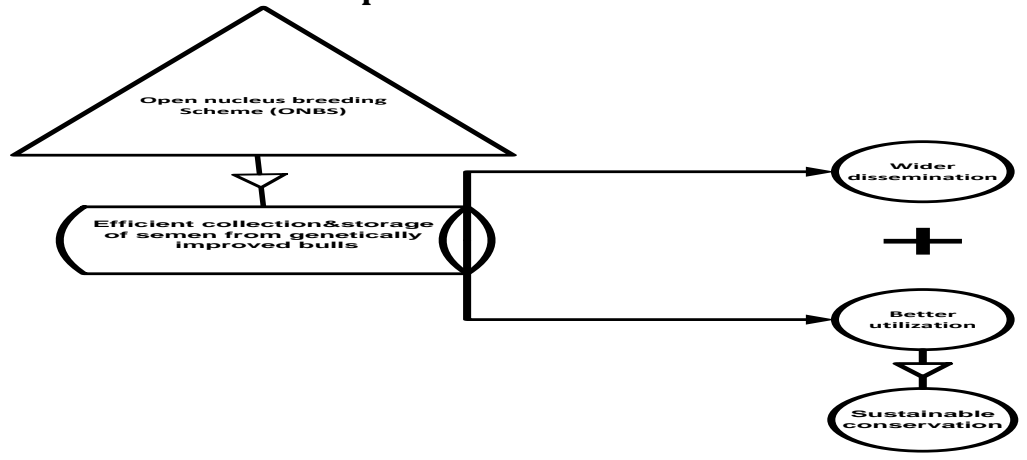

\section{Methodology}

The state of use of artificial insemination in Africa and the activities that are related to breeding and conservation of N'Dama cattle was assessed through information sources such as scientific articles, magazines, conference proceedings, reports, and publications of relevant organizations. The collated information also served as a basis for the design of questionnaire and focus group discussion interview guide (Rubin \& Babbie, 2009; Wong, 2008). Meanwhile, the breeding scheme of ITC in the Gambia was used as a case study.

Questionnaire: With the aim of evaluating the beliefs and intentions of the respondents concerning the adoption of AI, the questionnaire was designed based on the theory of planned behavior (Hardeman et al., 2002). The questions were answered on a 5-point Likert-type scale (Likert, 1932) although some questions were negatively phrased in order to ensure variations in responses. Overall, the questions were grouped into major six constructs: knowledge(A), perceived susceptibility(B), perceived severity(C), perceived barriers(D), attitudes towards behavior(E), and cues to action(F). In this regard, construct ' $\mathrm{A}$ ' evaluates the knowledge of the respondents on AI; 'B' examines what the respondents perceived as the technical effects of using AI; ' $\mathrm{C}$ ' measures the extreme cases that should be considered in the use of $\mathrm{AI}$; ' $\mathrm{D}$ ' tests the opinions of the respondents on what could be the constraints to using AI; 'E' contains questions on the prerequisites that will make AI appealing to farmers; ' $F$ ' evaluates the financial, technical and institutional factors that could influence the choice of using AI. Meanwhile, each construct on the average has 6 questions, which evaluates the essential factors to be considered with regard to the adoption of AI in a typical N'Dama cattle-breeding scheme. The questionnaire in an English language was pre-tested with potential respondents who were randomly chosen from the targeted population (Nicolaos, 2003). The feedbacks obtained from those participants were thereafter used to improve the final copy of the questionnaire.

Focus Group Discussion: In order to directly assess the opinions of farmers who are the main custodians of N'Dama cattle, three separate focus group discussions were held at Keneba, Niamina and Nianija intervention sites of ITC, the Gambia. In selecting the participating farmers, due attentions were given to societal issues such as age, gender and level of education. Also during the discussions, group dynamics, motivation and curiosity were ensured in order to generate enough responses from the participants. The discussion/interview guide, which has similar number of constructs like the questionnaire focused on $\mathrm{AI}$ and then the Gambian national policy. The discussions were conducted in the local languages (Fula, Madinka, and Wallof) of the participants while the note taking was done simultaneously by the researcher and a livestock assistant.

Analysis of the Questionnaire and Discussion Transcripts: The responses to 5-point Likert-type questionnaire were coded as 1 = "I strongly disagree"; 2 = I disagree"; 3 = "neutral" 4 = "I agree"; 5 = "I strongly agree" and analyzed on a stepwise basis with a Statistical Package for Social Sciences (IBM-SPSS ${ }^{\circledR}$ version 19.0). Variations among the stakeholders (apart from the illiterate farmers) in the N'Dama cattle management was evaluated across demographic variables such as age, gender, religion, highest level of education attained, type of profession, and experience level by using frequency counting and proportions. The independence of the questions (variables) in each construct was determined through a cross tabulation and Pearson's Chi-squared test. Meanwhile the internal consistence of each construct was measured using a 
reliability analysis (Gardner, 1995; Gliem \& Gliem, 2003). In this case, the decision to either retain or drop a variable in a construct was based on the value of Cronbach's Alpha coefficient (de Vaus, 2002; Floyd, 2009); any dropped variable was however found to be redundant. Furthermore, since it is unlikely for a single question in each construct to fully represent a theoretical concept of the subject matter, the scores of the questions in a construct (i.e. a total score per construct) were obtained (Spector, 1992). This step averages out the measurement errors (Nunnally \& Bernstein, 1994). Further analysis was based on total score per construct of each respondent. The number of components needed to explain the independence of the evaluated constructs was determined with the Principal Component Analysis (PCA). A careful examination of the underlying assumptions for appropriateness of the PCA such as sample size (107 in this case), ratio of sample size (number of respondents) to constructs $=107: 6$; presence of at least 2 correlations with values $>0.3$ in the correlation matrix of the variables; measure of sampling adequacy $(0.651>$ minimum 0.50$)$, and Bartlett's test of sphericity $(\mathrm{p}<0.05)$ were all satisfactory. To ensure that variance of the loadings within each component is maximized, Varimax was set as the rotation option while the latent root condition for number of components to be retained was based on Eigenvalue-one criterion (Tabachnick \& Fidell, 2001). In any case, a component is considered significant if its Eigenvalue is greater than 1. Based on the component plot of PCA for the constructs, 3 components were distinguishable. Therefore the constructs were regrouped into three main factors i.e. 'perceived susceptibility', 'stimulating factors' and 'limiting factors'. The degrees to which the respondents agree, remain neutral or disagree with the retained questions in each construct were reported. The transcripts from focus group discussions similarly written as the constructs used in the questionnaire were first reviewed and later analyzed by content analysis method (Weber, 1990). To concisely express all the relevant statements, emphasis was given to the patterns and trend of the identified common keywords. Aggregation of the respondents' statement based on relevance to the research questions was done by placing them side by side. The summary of the discussions are presented in the result section.

\section{Results}

Potential Factors Influencing the Use of AI for Disseminating N'Dama Bulls: The respondents classified as stakeholders in this research and sorted according to their demographic variables are as shown in Table 1 below. These stakeholders (apart from the illiterate farmers) were older than 18 years of age and of which a total of $95.1 \%$ have at least had a basic secondary school education. Meanwhile, there was a narrow variation in terms of religion and gender. This set of information on the distribution of stakeholders is important for making decisions on the possibility of using AI. In addition, any policy process on the conservation of N'Dama cattle should needs to consider this observed variation in the distribution of stakeholders. As also shown in Table 2, the first glance into the constructs tested in this survey indicates that the construct 'attitudes toward behavior' $(E)$ has the highest significant correlations $(p<0.01)$ with the other constructs. In other words, this is the construct, which is mostly related to the other ones and therefore needs to be given a high consideration in deciding on the factors that influence the adoption of AI for disseminating genetically improved bulls. In addition, it means that the tested variables in the other constructs are highly dependent on the variables grouped in construct 'E'. Meanwhile, the construct 'Perceived susceptibility' (B) and 'Perceived barriers' (D) were negatively correlated but not statistically significant.

By using, the Principal Component Analysis (PCA) as a statistical data summarizing method, the construct ' $\mathrm{A}$ ' was dropped off after the first iteration because of its low communality. After the second iteration of the procedure, only 3 components $(\mathrm{B}, \mathrm{C}+\mathrm{D}$, and $\mathrm{E}+\mathrm{F})$ as shown in Figure 2 were identified. In other words, these 3 components represent the independence of the constructs that were tested in this survey. Taking clues from the component plot, an overall summary was done by grouping the variables (questions) in the evaluated construct into three distinguishable factors namely: (1) Potential Effects (B = perceived susceptibility); (2) Stimulating Factors ( $\mathrm{E}=$ attitudes toward behavior $+\mathrm{F}=$ cues to action) and (3) Limiting Factors $(\mathrm{C}=$ perceived severity $+\mathrm{D}=$ perceived barriers)'. 
Table 1: Demographic Information of N'Dama Stakeholders

\begin{tabular}{|c|c|c|c|}
\hline Variables & Categories & Frequency counts & Valid Percent (\%) \\
\hline \multirow{6}{*}{$\begin{array}{l}\text { Stakeholders' } \\
\text { groups }\end{array}$} & N'dama Cattle Owners & 46 & 42.6 \\
\hline & Agricultural Officers & 25 & 23.1 \\
\hline & Livestock Technicians & 10 & 9.3 \\
\hline & Veterinarians & 9 & 8.3 \\
\hline & Scientists & 10 & 9.3 \\
\hline & Policymakers & 8 & 7.4 \\
\hline \multirow[t]{3}{*}{ Age } & $0-18$ & 0 & 0 \\
\hline & $19-50$ & 65 & 60.7 \\
\hline & $>50$ & 42 & 39.3 \\
\hline \multirow[t]{2}{*}{ Gender } & Man & 92 & 92.9 \\
\hline & Woman & 7 & 7.1 \\
\hline \multirow[t]{3}{*}{ Religion } & Islam & 100 & 92.6 \\
\hline & Christianity & 4 & 3.7 \\
\hline & Other & 2 & 1.9 \\
\hline \multirow{3}{*}{$\begin{array}{l}\text { Number of years in } \\
\text { practice }\end{array}$} & $0-10$ & 34 & 31.8 \\
\hline & $11-20$ & 22 & 20.6 \\
\hline & $>20$ & 51 & 47.7 \\
\hline \multirow{5}{*}{$\begin{array}{l}\text { Highest level of } \\
\text { education attained }\end{array}$} & Non-formal Education & 5 & 4.8 \\
\hline & Basic Education (grades 1-9) & 10 & 9.6 \\
\hline & Senior Secondary Level & 31 & 29.8 \\
\hline & University Level & 33 & 31.7 \\
\hline & Others (college, technical schools) & 25 & 24.0 \\
\hline
\end{tabular}

Table 2: Inter-item Correlation Matrix of the Constructs

\begin{tabular}{lllllll}
\hline \multicolumn{7}{c}{ Questionnaire constructs } \\
\cline { 2 - 6 } & $\mathbf{A}$ & $\mathbf{B}$ & $\mathbf{C}$ & $\mathbf{D}$ & $\mathbf{E}$ & $\mathbf{F}$ \\
\hline $\mathrm{A}$ & .00 & & & & \\
$\mathrm{~B}$ & $0.385^{* *}$ & .00 & & & & \\
$\mathrm{C}$ & 0.077 & 0.086 & .00 & & & \\
$\mathrm{D}$ & $.203^{*}$ & -0.026 & $0.293^{* *}$ & .00 & & \\
$\mathrm{E}$ & $0.387^{* *}$ & $0.399^{* *}$ & $0.368^{* *}$ & $.210^{*}$ & .00 & \\
$\mathrm{~F}$ & $0.306^{* *}$ & $0.449^{* *}$ & 0.050 & .115 & $.283^{* *}$ & .00 \\
\hline ** Correlation is significant at the 0.01 level (2-tailed); ${ }^{*}$ Correlation is significant at the 0.05 level (2-tailed).
\end{tabular}

Figure 2: Component Plot of the Constructs

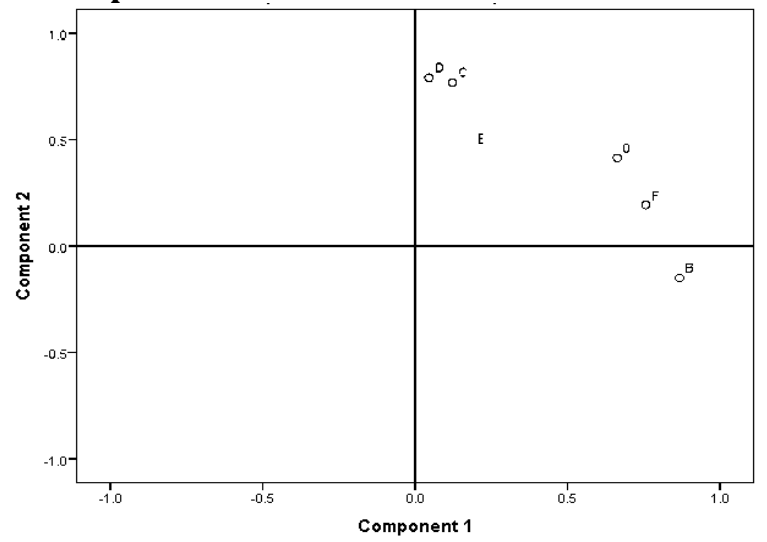

Therefore as summarized in Table 3A, the 6 potential effects that the use of AI can generate were identified. More than $50 \%$ of the total respondents agreed that AI can result in conservation of N'dama cattle breed, increased offspring per animal, higher selection intensity, and better gene flow at different levels of ONBS. 
However, the response did not differ considerably with regard to whether the use of AI can enhance genetic diversity given a phenomenon like inbreeding depression. On a further note, more than an average number of the respondents perceived high financial requirement, complex logistical operations, and quality of the semen as factors that will limit the use of AI for disseminating N'Dama cattle bulls. Technically, the low pregnancy rate, inadequate expertise of AI technicians, farmers' inadequate knowledge of detecting animals in heat and in keeping breeding records were further identified as limiting factors for adopting AI as a reproductive technology in a typical setting like that of ITC, the Gambia. Interestingly, nearly half $(46.2 \%)$ of the respondents did not consider the extensive method of N'Dama husbandry as a potential factor that can hinder the use of AI. Concerning the factors that can stimulate the use of $\mathrm{AI}$ in a purebreeding scheme, more than $65 \%$ of the respondents agreed that a clear breeding objective, involvement of breeders' organizations, and use of incentives in a form of price subsidy are essential requirements. Similarly, establishment of AI camps at community levels, availability of financial and technical support, animal genetic resources (AnGR) related policies were identified. Meanwhile none of the respondents disagrees with the notion that educational campaign is a priority in stimulating the use of AI for an N'Dama purebreeding system.

Table 3A: Potential Effects of Adopting AI for Disseminating N'Dama Bulls

\begin{tabular}{llllll}
\hline A. Potential Effects & $\begin{array}{l}\text { Agree } \\
(\mathbf{\% )}\end{array}$ & $\begin{array}{l}\text { Neutral } \\
\mathbf{( \% )}\end{array}$ & $\begin{array}{l}\text { Disagree } \\
\mathbf{( \% )}\end{array}$ & $\mathbf{N}$ & S.E.M. \\
\hline Conservation of N'dama cattle breed & 7.4 & 1.3 & 1.3 & 06 & .066 \\
High selection intensity & 8.5 & 7.0 & 5.4 & 07 & 0.079 \\
Improved exchange of semen at different levels of ONBS & 0.0 & 2.3 & 7.7 & 06 & 0.055 \\
Improved gene flow in a pure breeding system & 9.8 & 7.0 & 3.2 & 05 & 0.078 \\
Increased offspring per animal & 9.8 & .7 & 0.8 & 06 & 0.059 \\
Maintenance of genetic diversity & 1.5 & 2.3 & 6.2 & 06 & 0.083 \\
\hline
\end{tabular}

Table 3B: Summary of the Stimulating Factors Influencing the Adoption of AI

\begin{tabular}{llllll}
\hline B. Stimulating Factors & $\begin{array}{l}\text { Agree } \\
\text { (\%) }\end{array}$ & $\begin{array}{l}\text { Neutral } \\
\text { (\%) }\end{array}$ & $\begin{array}{l}\text { Disagree } \\
\text { (\%) }\end{array}$ & N & S.E.M. \\
\hline Animal genetic resources (AnGR) related policies & 1.9 & 10.5 & .6 & 105 & 0.057 \\
Capacity building of extension agents and technicians & 6.7 & .7 & .6 & 105 & 0.055 \\
Clear national breeding objective & 7.1 & 5.2 & .6 & 105 & 0.059 \\
Educational campaigns & 1.4 & 8.6 & - & 105 & .027 \\
Establishment of AI camps at community levels & 4.6 & 12.5 & 2.9 & 104 & .045 \\
Financial and technical support & 7.2 & .3 & .7 & 07 & .044 \\
Highly functioning breeding organizations & 4.5 & 1.8 & 3.7 & 02 & .071 \\
Introduction of AI into the existing ONBS & 0.1 & 2.4 & .5 & 07 & .060 \\
Involvement of breeders' organizations & 8.6 & 8.7 & 12.6 & 03 & .068 \\
Public funding by the government, NGOs, etc. & 4.4 & 5.4 & 0.2 & 04 & .079 \\
Use of incentives in a form of price subsidy & 9.0 & 5.2 & 5.7 & 05 & .084 \\
\hline
\end{tabular}

Table 3C: Summary of the Limiting Factors Influencing the Adoption of AI

\begin{tabular}{lllllc}
\hline C. Limiting Factors & $\begin{array}{l}\text { Agree } \\
(\mathbf{\%})\end{array}$ & $\begin{array}{l}\text { Neutral } \\
(\mathbf{\%})\end{array}$ & $\begin{array}{l}\text { Disagree } \\
\mathbf{( \% )}\end{array}$ & $\mathbf{N}$ & S.E.M \\
\hline Complex logistical operations & 9.8 & 7.0 & 3.2 & 106 & 0.093 \\
Farmer's inability to detect heat period & 0.0 & 2.3 & 37.7 & 106 & 0.121 \\
Farmers' inadequate knowledge of keeping breeding & 5.0 & 7.5 & 7.5 & 107 & 0.092 \\
records & & & & & \\
High amount of initial capital & 3.6 & 7 & 0.8 & 106 & 0.108 \\
Inadequate knowledge of the AI technicians & 7.5 & 7.0 & 5.5 & 106 & 0.117 \\
Low pregnancy rate & 5.7 & 5.5 & 8.9 & 106 & 0.098 \\
Quality of the semen & 8.5 & 7.0 & 5.4 & 106 & .106 \\
Restriction to periurban areas only & 4.0 & 3.5 & 2.5 & 104 & .083 \\
**N is the total number of responses for each variable; S.E.M. is the error associated with the summary hereby \\
presented.
\end{tabular}


Possibility of AI in an Open Nucleus Breeding System (ONBS): Farmers' Perspective: The focus group discussion held with farmers in the Gambia further proved that a relatively large proportion $(>80 \%)$ of these custodians of animals keep N'dama cattle for both economic and cultural purposes. In addition, the N'Dama cattle farmers indicated that this breed is highly adaptive to the local environment when compared to other familiar breeds such as Gobra and Macha (Gobra x N'Dama). Concerning the knowledge of these farmers on the possibility of using AI for disseminating the bulls from the nucleus-breeding scheme, $80 \%$ of this group indicated that they have not had such a practical opportunity to use AI. However, they were aware of this reproductive technology through documentary, reading of books and learning from the experience of their neighboring Senegalese farmers. A very few farmer who were beneficiaries of the F1 programme (crossbreeding of N'Dama cattle with Holstein Friesian and New Jersey) in 1999/2000 also narrated their experiences. The farmers realized that with AI, calving interval could be shortened and there is an added advantage of having calves at any time of the year. In addition, wider dissemination of semen from a proven bull, twin-calf birth, access to genetically superior bulls is some of the benefits that will make AI beneficial to the farmers. However, the often-required activities such as confinement of animals for estrous synchronization and the difficulty, which would be encountered in providing supplementary feed, are the likely barriers. Other limiting factors include low success rate of insemination and lack of post-insemination supervision by the government officials. Further thoughts beyond those limitations mentioned above, the farmers indicated a higher preference for the semen from genetically proven N'Dama bulls to the exotic breeds on the premise that exotic breed could not tolerate the local climatic and veterinary conditions.

Impacts of Existing National Policies: The interviewed farmers indicated a good knowledge of the need to conserve their indigenous breeds of animals including the N'Dama breed of cattle. In this regard, their conservation practice often includes a good monitoring of their herds of cattle in order to prevent indiscriminate crossbreeding with other neighboring breeds. Based on a general consensus, the farmers revealed that they were not aware of any Gambian national or agricultural policy, which specifically addresses the issue of N'Dama cattle conservation. However, the farmers through the awareness of environmental policy always protect the forest zones by avoiding tree felling, bush burning or any other activity that could lead to destruction of the natural habitats where endemic animals are raised. Nevertheless, dissatisfaction was expressed by the farmers concerning unfairness in policymaking process (for instance, sidelining of the farmers) and inadequate compensation for compliance to government initiatives like tax payment. The farmers expressed willingness to learn more about national agricultural policies of the Gambia and how it relates to conservation of animal genetic resources through mediums such as workshops, printed materials, radio programs and local leaders.

\section{Conclusion}

Interestingly, the possibility of disseminating genetically improved N'dama bulls with AI in order to support sustainable use and conservation of the breed can be considered feasible given some stimulating factors such as educational campaigns, capacity building of extension agents, and availability of subsidy on insemination price. However from a theoretical point of view and specifically with respect to avoidance of an inbreeding depression, the small base population of N'Dama cattle at ITC station and in the Gambia as a whole are additional limiting factors to the use of AI. Furthermore, the existing technical capacity and infrastructural facilities at ITC are not enough to guarantee a successful application of AI. As a first-hand option in solving the challenge of limited bulls that can be disseminated to the farmers for further breeding activities, it is recommended that the nucleus station herd should be increased. Also as an alternative to the phenotypic selection currently being used, a marker-assisted selection (MAS) can be additionally evaluated and adopted. With the MAS, the bulls can be tested and selected at a relatively young age and therefore be ready for an onward dissemination to the eagerly waiting farmers. The importance of a national policy for breeding and conservation of endemic animals like N'Dama cattle cannot be overemphasized. The effects of such policies can be about the protection of natural habitats where endemic animals are reared. To encourage a better compliance to policies, the farmers desired that more flexibility and their own involvement be considered in policymaking process. Furthermore, the policies need to be clearly communicated to them through workshops and local leaders. The use of day-to-day activities and circumstances are also recommended in this perspective. Specifically for the Gambia, taking clues from the way through which the environmental 
policies in this country are presently implemented will be an effective step in ensuring an effective implementation of other closely related national policies.

\section{References}

De-Vaus, D. A. (2002). Surveys in Social Research. Allen \&Unwin, Crows Nest, Australia, 379.

Dempfle, L. \& Jaitner, J. (2000). Case Study About the N'Dama Breeding Programme at the International Trypanotolerance Centre (ITC) in The Gambia. Paper presented at the Workshop on Developing Breeding Strategies for Lower Input Animal Production Environments, Bella, Italy.

Floyd, J. F. (2009). Survey Research Methods. Thousand Oaks, USA: Sage Publications.

Gardner, P. L. (1995). Unidimensionality and Internal Consistence Revisited. Research in Science Education, 25, 238-289.

Gliem, J. A. \& Gliem, R. R. (2003). Calculating, Interpreting, and Reporting Cronbach's Alpha Reliability Coefficient for Likert-Type Scales. Retrieved from http://hdl.handle.net/1805/344

Hardeman, W., Johnston, M., Johnston, D. W., Bonetti, D., Wareham, N. J. \& Kinmonth, A. L. (2002). Application of the Theory of Planned Behaviour in Behaviour Change Interventions: A systematic Review. Psychology \& Health, 17(2), 123-158.

Kahi, A. K. \& Rewe, T. O. (2008). Biotechnology in livestock production: Overview of possibilities for Africa. African Journal of Biotechnology, 7 (25), 4984-4991.

Likert, R. (1932). A technique for the Measurement of Attitudes. Archives of Psychology, 22(140), 1-55.

Mattioli, R. C., Pandey, V. S., Murray, M. \& Fitzpatrick, J. C. (2000). Immunogenetic Influences on Tick Resistances in African Cattle with Particular Reference to Trypanotolerant N'Dama (Bos taurus) and Trypanosusceptible Gobra Zebu (Bos indicus) Cattle. Acta Tropics, 75(3), 93-103.

Nicolaos, E. S. (2003). The Art of Questionnaire Construction: Some Important Considerations for Manufacturing Studies. Integrated Manufacturing Systems, 14(3), 221-237.

Notter, D. R. (2004). Conservation Strategies for Animal Genetic Resources. Food and Agriculture Organization Background Study Paper No. 22. Retrieved August 13, 2011, from ftp://ftp.fao.org/docrep/fao/meeting/015/j3568e.pdf

Nunnally, J. C. \& Bernstein, I. H. (1994). Psychometric Theory (3rd ed.). New York: McGraw-Hill.

Rubin, A. \& Babbie, E. R. (2009). Research Methods for Social Work (2nd ed.). Belmont, CA: Brooks/Cole.

Spector, P. (1992). Summated Rating Scale Construction. Thousand Oaks, USA: Sage Publications Inc.

Tabachnick, B. G. \& Fidell, L. S. (2001). Using Multivariate Statistics (4th ed.). Boston, MA: Allyn \& Bacon.

Van-Arendonk, J. A. M. (2011). The role of reproductive technologies in breeding schemes for livestock populations in developing countries. Livestock Production Science, 136, 29-37.

Weber, R. P. (1990). Basic Content Analysis. Newbury Park, CA: Sage Publications Inc.

Wong, L. P. (2008). Focus Group Discussion: A Tool for Health and Medical Research. Singapore Medical Journal, 49(3), 256-261. 